\title{
Identification of a spliced gene from duck enteritis virus encoding a protein homologous to UL15 of herpes simplex virus 1
}

\author{
Hongwei Zhu, Huixin Li, Zongxi Han, Yuhao Shao, Yu Wang and Xiangang Kong*
}

\begin{abstract}
Background: In herpesviruses, UL15 homologue is a subunit of terminase complex responsible for cleavage and packaging of the viral genome into pre-assembled capsids. However, for duck enteritis virus (DEV), the causative agent of duck viral enteritis (DVE), the genomic sequence was not completely determined until most recently. There is limited information of this putative spliced gene and its encoding protein.

Results: DEV UL15 consists of two exons with a 3.5 kilobases (kb) inron and transcribes into two transcripts: the full-length UL15 and an N-terminally truncated UL15.5. The $2.9 \mathrm{~kb}$ UL15 transcript encodes a protein of 739 amino acids with an approximate molecular mass of 82 kiloDaltons ( $\mathrm{kDa}$ ), whereas the UL15.5 transcript is $1.3 \mathrm{~kb}$ in length, containing a putative 888 base pairs (bp) ORF that encodes a $32 \mathrm{kDa}$ product. We also demonstrated that UL15 gene belonged to the late kinetic class as its expression was sensitive to cycloheximide and phosphonoacetic acid. UL15 is highly conserved within the Herpesviridae, and contains Walker A and B motifs homologous to the catalytic subunit of the bacteriophage terminase as revealed by sequence analysis. Phylogenetic tree constructed with the amino acid sequences of 23 herpesvirus UL15 homologues suggests a close relationship of DEV to the Mardivirus genus within the Alphaherpesvirinae. Further, the UL15 and UL15.5 proteins can be detected in the infected cell lysate but not in the sucrose density gradient-purified virion when reacting with the antiserum against UL15. Within the CEF cells, the UL15 and/or UL15.5 localize(s) in the cytoplasm at $6 \mathrm{~h}$ post infection (h p. i.) and mainly in the nucleus at $12 \mathrm{~h} \mathrm{p.} \mathrm{i.} \mathrm{and} \mathrm{at} 24 \mathrm{~h} \mathrm{p}$. i., while accumulate(s) in the cytoplasm in the absence of any other viral protein.

Conclusions: DEV UL15 is a spliced gene that encodes two products encoded by 2.9 and $1.3 \mathrm{~kb}$ transcripts respectively. The UL15 is expressed late during infection. The coding sequences of DEV UL15 are very similar to those of alphaherpesviruses and most similar to the genus Mardivirus. The UL15 and/or UL15.5 accumulate(s) in the cytoplasm during early times post-infection and then are translocated to the nucleus at late times.
\end{abstract}

\section{Background}

Duck enteritis virus (DEV), also known as Anatid herpesvirus-1 (AHV-1), is an important pathogen of birds of the order Anseriformes, including ducks, geese and swans, causing the acute contagious disease duck viral enteritis (DVE) or duck plague (DP), which results in substantial mortality and reduction of egg production in domestic as well as in wild waterfowl $[1,2]$. DEV was classified as an unassigned virus within the family

\footnotetext{
* Correspondence: xgkong@hvri.ac.cn

Division of Avian Infectious Diseases, State Key Laboratory of Veterinary Biotechnology, Harbin Veterinary Research Institute, the Chinese Academy of Agricultural Sciences, Harbin 150001, China
}

Herpesviridae according to the Eighth International Committee on Taxonomy of Viruses (ICTV) [3]. Evidence from recent phylogenetic analysis of the nucleotide sequence or the predicted amino acid sequence suggests that DEV was closely related to the genus Mardivirus or Varicellovirus and might represent a single cluster within the subfamily Alphaherpesvirinae [4-8].

The genomic sequence of DEV was determined and analyzed recently and the presence of more than 78 different open reading frames (ORFs) was predicted [8]. A terminase-related, protein-encoding gene homologous to HSV UL15 was predicted based on the homology analysis of theses ORFs and those of their homologous 
counterparts from other herpesviruses. The UL15 is a rarely occurring spliced gene in herpesviruses and consists mostly of two exons [9-15]; however, there are three exons in UL15 homologue from the channel catfish herpesvirus [16]. UL15 is highly conserved among members of the family Herpesviridae, which implies the functional significance of this protein [9]. The amino acid sequence of UL15 shares homology with the large subunit of the terminase complex of bacteriophage T4, particularly with respect to the two nucleotide-binding motifs of the ATP-binding domain known as Walker A and Walker B domains [16,17], which suggests UL15 is ATP binding as demonstrated for gp17 and other phage terminases [18].

Within the infected cells, UL15 and at least other six proteins (UL6, UL17, UL25, UL28, UL32 and UL33) are involved in viral DNA cleavage and packaging [19-25]. In accordance with the defined role as a terminase subunit, the UL15 protein is presumed to localize or colocalize with other subunits primarily within the nucleus of infected cells. Indeed, HSV-1 UL15 is transported from intranuclear space at $6 \mathrm{~h}$ post-infection (h p. i.) into the nucleus at $12 \mathrm{~h} \mathrm{p}$. i. and localizes to the replication compartments where cleavage and packaging proteins might be recruited to process the viral DNA, as indicated by immunofluorescence assay $[21,26]$. In addition, the ORF45/42 gene product, a UL15 homologue in varicella-zoster virus (VZV), also shows nearly exclusive nuclear localization in infected cells [14]. In contrast to its HSV-1 homologue, cells transiently transfected with ORF45/42 showed only weak nuclear staining, which suggests the formation of a protein complex, or at least a heterodimers, by UL15 homologues and other putative terminase subunit(s). Such a terminase complex has been studied extensively in HSV-1 [27-29] and in human cytomegalovirus (HCMV) [30].

In DEV, the UL15 transcript feature and its encoding product were analyzed merely on the basis of the sequence alignment with its counterparts from other herpesviruses. Little is known about this, or at least possible, spliced gene and its product in DEV-infected cells or DEV virion. Therefore, we describe the identification and characterization of the putative UL15 transcript and its encoding protein in DEV-infected cells, which provides data to aid the classification of DEV within the Herpesviridae family and provides clues for better understanding the possible role of UL15 in DEV infection.

\section{Results}

\section{UL15 is a spliced gene with two transcripts}

Nucleotide sequence of the putative DEV UL15 gene was determined, annotated and deposited in GenBank (accession numbers EF524094 and EF203707) previously by our laboratory. The UL15 gene of DEV is assumed to consist of two coding exons separated by an intron that contains ORFs UL16 and UL17 transcribed in the orientation opposite to that of UL15 [8]. To confirm this assumption, RT-PCR was carried out with RNA isolated from DEV-infected CEF cells with specific primers covering the putative splice site. As expected, a $786 \mathrm{bp}$ DNA product was observed by electrophoresis in agarose gel (Figure 1A). The fragment was cloned and sequenced, and the splice site was located. The genomic sequences at the exon-intron boundaries were found to read 5'- GCATTGACAGgtacttgtct-3' and 5'-aacaactaagAGTTTGCGAG-3' (intron sequences are indicated in lowercase letters) as donor and splicing acceptor sequences respectively (Figure 1B), conforming to the consensus of the GT-AG rule [31].

The UL15 transcript was determined by northern blot analysis of total RNA isolated from mock-infected or DEV-infected cells. The results demonstrated that UL15 is transcribed with a predominant transcript of $2.9 \mathrm{~kb}$ and a less abundant transcript of $1.3 \mathrm{~kb}$ when hybridizing the blot with probes $\mathrm{P}^{898}$ and $\mathrm{PC}^{696}$ (Figure 2A). We believed that the $2.9 \mathrm{~kb}$ transcript corresponded in size to the UL15 transcript, while the $1.3 \mathrm{~kb}$ transcript corresponded in size to the predicted UL15.5 transcript.

\section{Sequence analysis of DEV UL15}

The complete nucleotide sequence of the UL15 transcript is $2882 \mathrm{bp}$ in length according to the 5'- and 3 '-RACE, and the putative coding region is $2220 \mathrm{bp}$ in length, encoding a 739 amino acid protein with a calculated molecular mass of $82.1 \mathrm{kDa}$. The UL15.5 transcript is $1290 \mathrm{bp}$ in length with an $888 \mathrm{bp}$ ORF that encodes a $32.1 \mathrm{kDa}$ protein. The transcription start site (TSS) of UL15 is 612 bp upstream from the putative start codon ATG and that of UL15.5 is 352 bp upstream from the ATG codon. Promoters as well as TATA box elements of UL15 and UL15.5 were predicted at the 5'-cDNA end (Figure 2B). In addition, a consensus polyadenylation site (5'-AATAAA-3') was present 18 bp downstream from the UL15 stop codon. 14 bp downstream, this signal is 12 adenine residues, as indicated by 3'-RACE sequencing (Figure $2 \mathrm{~B}$ ); this polyadenylation site could define the 3' ends of both the UL15 and UL15.5 transcripts. The UL15 gene locus was thus drawn accordingly (Figure 2C).

As shown in Table 1, homologues of the DEV UL15 gene product are conserved among subfamilies of the Herpesviridae. UL15 shares a high level of amino acid sequence identity $(32.9-62.3 \%)$ and similarity (50.3 $75.2 \%$ ) with nine other typical herpesviruses, as indicated by sequence alignments. Furthermore, two putative nucleotide-binding motifs, resembling the Walker A motif (GXXGXGKT/S, where X is any amino acid) and 


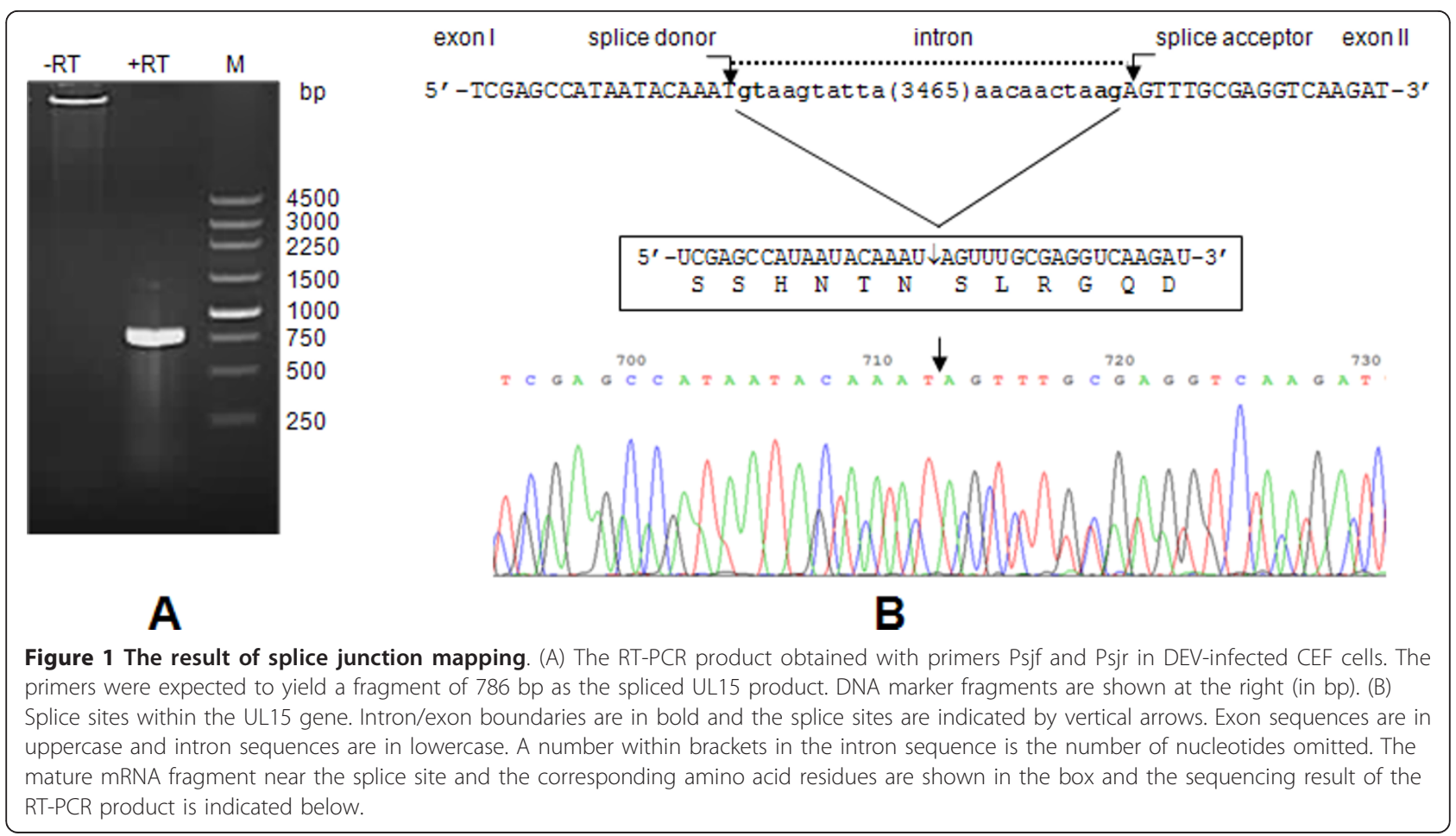

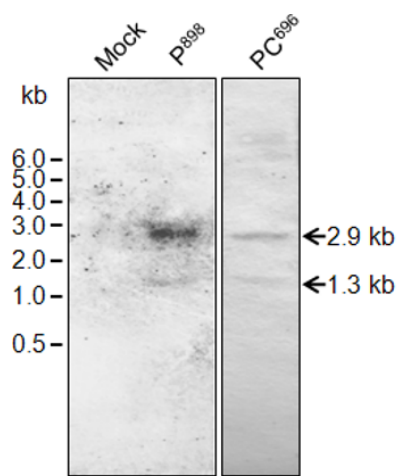

A
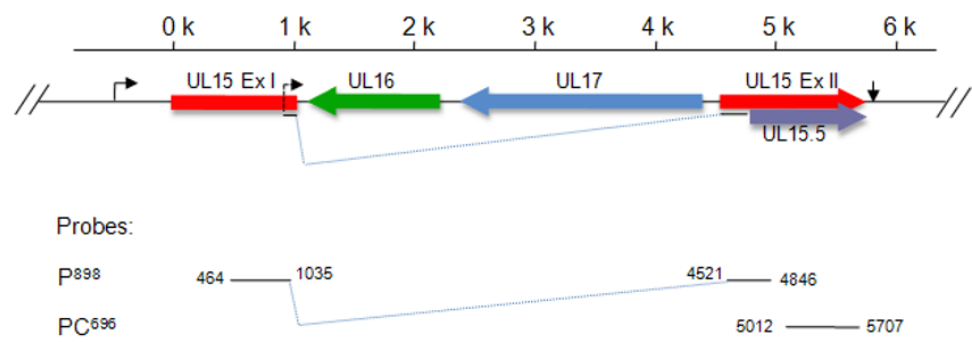

C

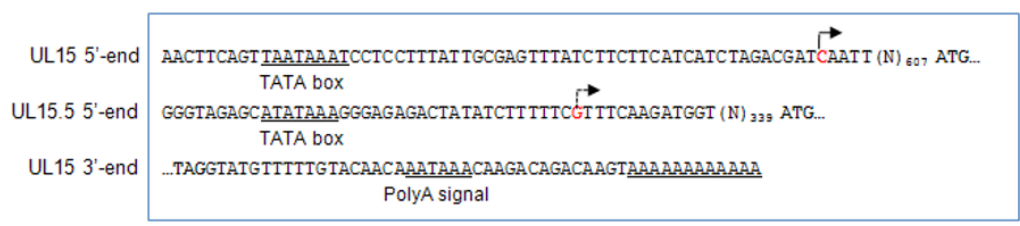

\section{B}

Figure 2 Schematic diagram of the UL15 gene. (A) Northern blot hybridization. Total RNA was isolated from DEV-infected CEF cells at $48 \mathrm{~h}$ p. i. RNA samples were then separated, blotted and hybridized with the probes and analyzed. The size of the mRNA was calculated according to the RNA size standard shown at the left. (B) The CDNA ends of UL15 and UL15.5. The promoters were predicted on the Berkeley Drosophila Genome Project's neural network promoter search engine (http://www.fruitfly.org/seq_tools/promoter.html). The TATA box and poly (A) signal elements were predicted on the TRANSFAC motif library (http://motif.genome.jp/) and the POLYADQ polyadenylation (polyA) signal search engine (http://rulai.cshl.org/tools/polyadq/polyadq_form.html), respectively. The predicted promoter sequences of UL15 and UL15.5 are shown, the TATA box, polyA signal motifs and polyA sequences are underlined, and the TSSs indicated by 5'-RACE are shown in red. The putative start and stop codons are in bold. (C) The DEV UL15 gene consists of two exons, exon I (Ex I) and exon II (Ex II), which are indicated by red arrows. The putative UL16 (green) and UL17 (blue) are located in the opposite orientation within the intron of UL15. The UL15 transcription start sites (TSS) and poly (A) sequences are indicated by black arrows. The UL15.5 TSS is indicated by the dashed arrow within Ex I of UL15. The ruler above the locus shows the relative position of the genes in $\mathrm{kb}(\mathrm{K})$. 
Table 1 Amino acid sequence similarity of DEV UL15 to terminase homologs from other nine herpesviruses

\begin{tabular}{llll}
\hline Viruses & $\begin{array}{l}\text { UL15 } \\
\text { homologues }\end{array}$ & $\begin{array}{l}\text { Identity } \\
\text { percentage }\end{array}$ & $\begin{array}{l}\text { Similarity } \\
\text { percentage }\end{array}$ \\
\hline HSV-1 & UL15 & 59.6 & 74.9 \\
HVT & UL15 & 62.3 & 75.2 \\
MDV-1 & UL15 & 58.2 & 73.4 \\
VZV & ORF42/45 & 56.0 & 72.9 \\
ILTV & UL15 & 46.4 & 61.9 \\
PRV & UL15 & 52.8 & 64.7 \\
HCMV & UL89 & 36.9 & 52.2 \\
MCMV & M89 & 36.5 & 53.8 \\
EBV & BGRF1/BDRF1 & 32.9 & 50.3 \\
\hline
\end{tabular}

the Walker B motif (ZZZZD or ZZZZDE, where Z is a hydrophobic amino acid) exist within the UL15 ORF. These two characteristic motifs were found to read ${ }_{261}$ VPRRHGKT $_{267}$ and ${ }_{354} \mathrm{LLFVDE}_{359}$, and fit neatly with those from typical subfamilies Alphaherpesvirinae (HSV1), Betaherpesvirinae (HCMV) and Gammaherpesvirinae (EBV), bacteriophage T4, bacteriophage P7 and bacteriophage HK97 (Figure 3).

Result from phylogenetic tree based on UL15 sequences of 23 herpesviruses showed that the DEV and other members in the Alphaherpesvirinae are clustered within a monophyletic clade with $100 \%$ bootstrap. Although the branch pattern of DEV UL15 shows distinctive character, its phylogenetic relationship in alphaherpesviruses, however, is still closely related to Mardivirus (Figure 4).

\section{UL15 is expressed late during infection}

To determine which kinetic class UL15 gene belongs to, RT-PCR was performed to detect UL15 and chicken $\beta$-actin mRNAs respectively in the presence of $\mathrm{CHX}$ or PAA. The result showed that the UL15 mRNA was not detected in DEV-infected cells in the presence of CHX or PAA, while the RT-PCR product could be amplified in the absence of these metabolic inhibitors; as a control, $\beta$-actin mRNA was insensitive to $\mathrm{CHX}$ or PAA (Figure 5A). Similar to the finding from RT-PCR, the UL15-specific immunoreactive bands were detected only in the absence of drug inhibitors, as shown by western blot (Figure 5B). Taken as a whole, treatment with CHX or PAA inhibited transcription and expression of UL15 in infected cells, suggesting that the UL15 gene is transcribed and expressed as a late gene during DEV infection in CEF cells.

\section{Detection of UL15 in infected cells and DEV virion}

To characterize the expression of the UL15 gene in infected cells, western blot was performed on the DEV infected or pcDNA-UL15 transfected CEF cell lysates using the UL15-specific antiserum developed in rabbits. We found that the antiserum could react with an $82 \mathrm{kDa}$ protein in DEV-infected CEF cell lysates, but not in uninfected cell extracts (Figure 6A). The protein was detectable at $6 \mathrm{~h} \mathrm{p}$. i. and the reactive band became stronger with time up to $24 \mathrm{~h}$ p. i. (Figure 6B). Further, the antiserum could react, although weakly, with a second polypeptide with molecular mass of $32 \mathrm{kDa}$ (Figure 6A), confirming the expression of the $1.3 \mathrm{~kb}$ transcript indicated by northern blot. We believe that this minor protein represents the UL15.5 of DEV. We also examined the DEV virion for its reactivity with anti-UL15 antiserum. As shown in Figure 6C, we were unable to detect UL15 in the prepared DEV virions, whereas the major capsid protein VP5 was detectable when reacting with $\mathrm{McAb} 1 \mathrm{~B} 5$. In addition, transfection of the pcDNA-UL15 plasmid into CEF could also result in the expression of UL15 (Figure 6D).

\section{Subcellular localization of the UL15 protein}

Subcellular distribution of DEV UL15 was determined by immunofluorescence assay of the DEV-infected CEF cells with anti-UL15 serum. As shown in Figure 7A, the fluorescence signals accumulated in the cytoplasm,

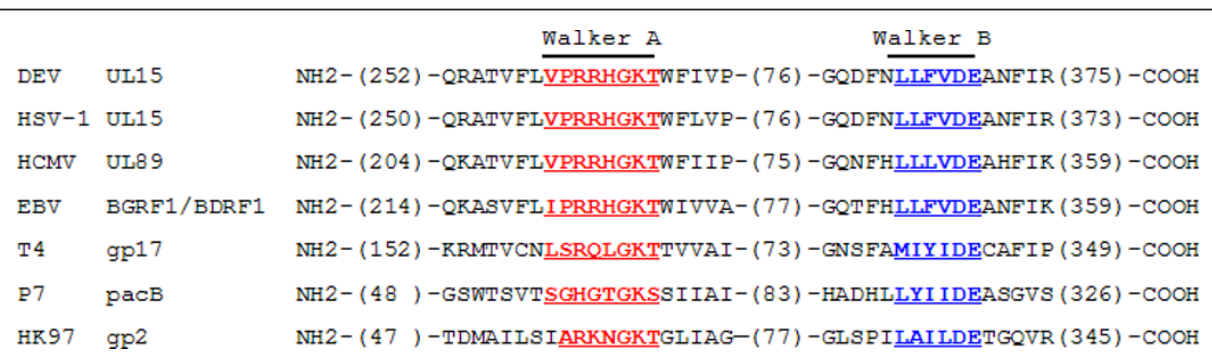

Figure 3 Alignment of potential ATPase domains of the large terminase subunit from herpesviruses and bacteriophages. Large terminase sequences of DEV(UniProtKB accession code C6ZD26), HSV-1 (P04295), HCMV (P16732), EBV (P03219), bacteriophage T4 (P17312), bacteriophage P7 (Q5XLR0) and bacteriophage HK97 (Q9MCT1) were aligned with the ClastalW2 multiple sequence alignment program [42]. The P7 terminase sequence was adjusted manually for the significant deviation in the distance between the motifs. The putative Walker A motifs of each sequence are underlined and in red and the Walker B motif are in blue. Numbers in brackets are the number of residues omitted. 


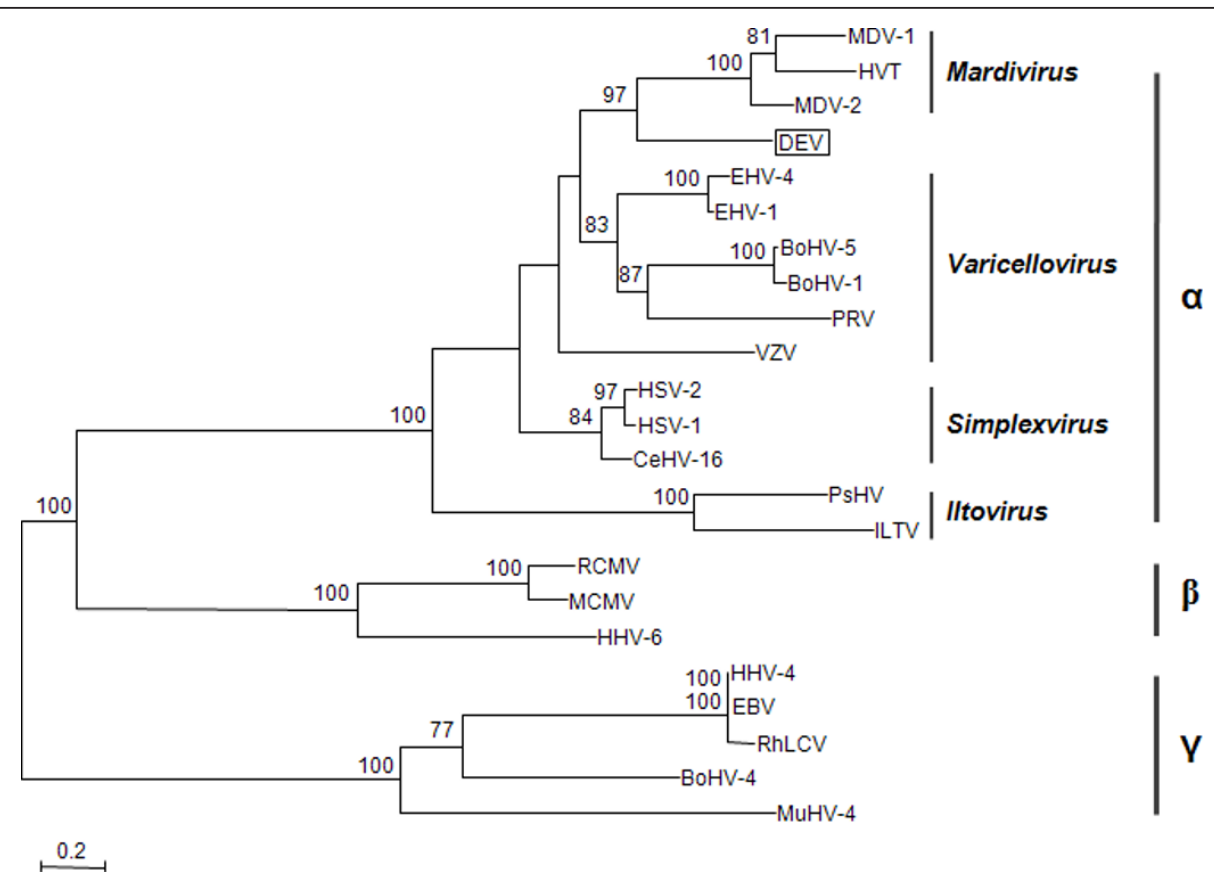

Figure 4 Phylogenetic tree based on the UL15 protein sequences of 23 herpesviruses. Amino acid sequences of UL15 homologues from 23 herpesviruses were retrieved and aligned using the ClustalW2 program. An unrooted phylogram was constructed using the PhyML software (version 3.0) with the LG amino acid substitution model and the non-parametric bootstrap support test. SeaView 4.1 was used for displaying and editing phylogenetic trees [43]. Values of bootstrap supports (100 replicates) in excess of $70 \%$ are shown on the shoulder of branches. The scale bar indicates 0.1 substitution/site and vertical lines are used to represent different subfamilies within the Herpesviridae and genera within the Alphaherpesvirinae.

predominantly in the perinuclear region of the cells in the early infection stage at $6 \mathrm{~h} \mathrm{p}$. i. At $12 \mathrm{~h}$ p. i. and $24 \mathrm{~h}$ p. i., however, the fluoresence signals localized mainly at the nucleus within the infected cells. Interestingly, at $24 \mathrm{~h}$ p. i., aggregation of fluorescence was observed occasionally within the nucleus ( $J$ and $L$ in Figure 7), which might represent the so-called replication compartments where viral DNA synthesis occurs, which has been observed in HSV-1 [32]. In addition, specific fluorescence was limited to the cytoplasm rather than in the nucleus in pcDNA-UL15 transfected CEF cells (Figure 7B), which may indicated that the UL15 and/or UL15.5 protein(s) could not transport through the nuclear pore, or possibly that the protein(s) retained in the cytoplasm as a result of interacting with certain cellular protein(s). Specific fluorescence signal was not detected in any assay in the mock-infected cells or pcDNA3.1 (+) transfected cells.

\section{Discussion}

It is common that eukaryotic DNA viruses encode genes containing introns that require mRNA splicing. However, the vast majority of transcripts are not spliced in viruses from the Herpesviridae. To our knowledge, aside from DEV UL15, there are four spliced UL15 homologues have been experimentally characterized in HSV-1, VZV, RCMV, Tupaia herpesvirus (THV) and Bovine herpesvirus 4 (BoHV-4) until now [9-12,14]. Remarkably in these five gene locus and other predicted homologues, we have noticed that although the coding sequences of UL15 homologues are conserved among herpesviruses, the ORFs and their arrangements between the exons are somewhat complex. In HSV-1, VZV and DEV, the intron contains two ORFs, UL16 and UL17, which have an orientation opposite to that of the UL15 gene [9,14]; in RCMV, the region between R89 (a UL15 homologue) exon 1 and exon 2 was found to contain five additional genes, r90, R91, R92, R93 and R94, the latter four are transcribed in the opposite orientation; in BoHV-4, the intron carries ORFs 30 - 33 in the opposite direction to UL15 homologues. It seems likely that the feature of gene arrangements within the introns is subfamily-specific within the Herpesviridae. This phenomenon might be the result of an evolutionary event: the terminase-related UL15 coding sequence remained conserved for its importance in herpesvirus biology, while genes within the intron evolved via recombination and gene transfer between virus and vertebrate hosts since these events are common in herpesviruses [33]. In this interpretation, the fact that the pattern of ORF organization within the DEV 

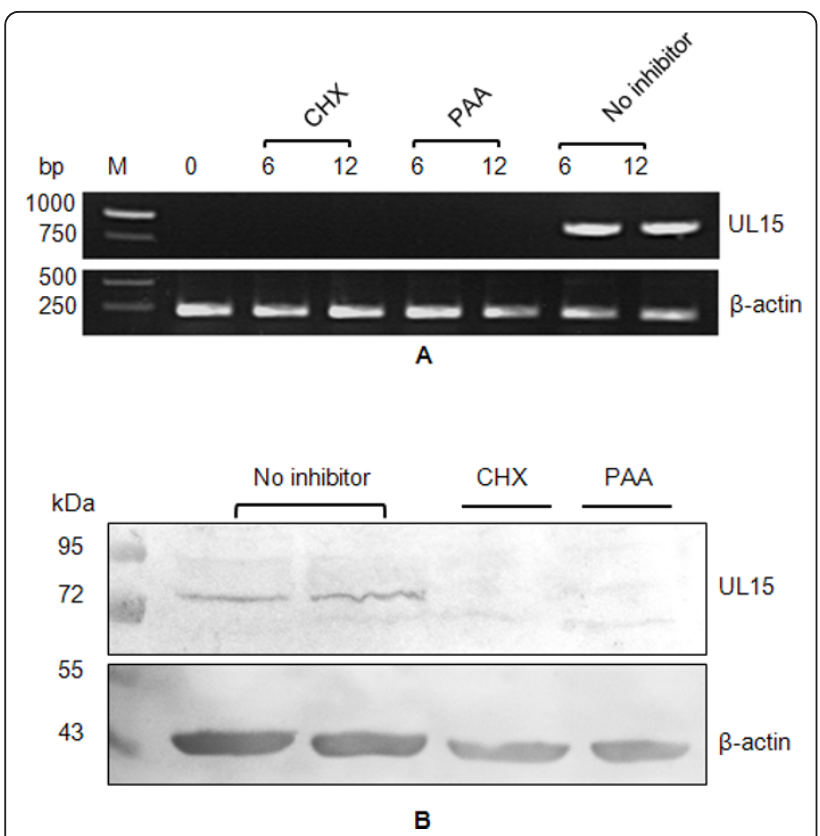

Figure 5 Kinetic class analysis of DEV UL15. DEV-infected CEF cells were harvested at the indicated time post-infection, followed by mRNA detection by RT-PCR (A) or protein detection by western blot (B). The procedures were done with $100 \mu \mathrm{g} / \mathrm{ml}$ cycloheximide $(\mathrm{CHX})$ or with $300 \mu \mathrm{g} / \mathrm{ml}$ phosphonoacetic acid (PAA) or without metabolic inhibitor as the control. Chicken $\beta$-actin mRNA or protein was used as an internal control.

UL15 intron is very similar to that of the corresponding regions of other alphaherpesviruses is another piece of direct evidence that DEV is a member of the subfamily Alphaherpesvirinae, which is in accordance with pervious findings $[4,6,7,34]$.

Two transcripts were detected using three different DIG-labeled DNA probes derived from the UL15 RTPCR product as indicated by northern blot (Figure 2A). Although choosing probes from the putative UL15 ORF could not exclude the possibility that either detected transcript was the result of overlapping transcripts adjacent to the UL15 gene or transcribing from the UL15 intron, subsequent results from full-length cDNA mapping by RACEs showed that both transcripts were most likely expressed by UL15, which is in good agreement with the two polypeptides detected by the UL15 antiserum. Thus, we believe that the $2.9 \mathrm{~kb}$ and $1.3 \mathrm{~kb}$ transcripts are analogous to the UL15 and UL15.5 of HSV-1, respectively. Besides, the $1.3 \mathrm{~kb}$ transcript hybridized with the probes $\mathrm{PC}^{696}$, which might suggest the C-terminal location of the UL15.5 transcript. Furthermore, pairwise alignment of DEV UL15 with HSV UL15.5 suggested the 295 residues of the DEV UL15.5 coding sequence, with its translation initiation site, might be located at Met ${ }^{445}$ within the DEV UL15 exon II. However, considering this methionine is not absolutely conserved among the herpesviruses family [16], whether this methionine is indeed an initiation site or translation of UL15.5 initiates at another site(s) requires further study. Interestingly, another four methionine residues $\left(\mathrm{Met}^{449}{ }^{4} \mathrm{Met}^{455}{ }^{4} \mathrm{Met}^{457}\right.$ and $\mathrm{Met}^{462}$ ) are present at this region only 4-17 residues downstream Met ${ }^{445}$, it is possible that when this site is mutated, another specific methionine might be utilized to translate a migrating version of UL15.5. In HSV-1, UL15.5 is dispensable for viral growth in the infected cell and its specific function during infection remains unknown, though several possible explanations for its origin and role have been discussed [26]. As for DEV UL15.5, further study is required to elucidate whether this gene is essential for DEV infection in vitro and in vivo, which will be a hint to specify the role(s) of UL15.5 itself as well as the C terminus of exon II concerning the largely identical sequences of the two.

In herpesviruses, there are several viral proteins participating in processing and packaging of viral DNA, among which UL15 homologue is a presumed terminase subunit with a potential role in the cleavage of progeny DNA [35]. The presence of the Walker A and Walker B box motifs in DEV UL15 might imply its corresponding role considering the following two facts: first, these two motifs fit well with the well characterized catalytic subunit (gp17) of the bacteriophage $\mathrm{T} 4$ terminase (Figure 3 ), similar position and distance between the motifs will ensure the correct formation of the nucleotide-binding site of an ABC (ATPbinding cassette) domain. Second, the role of the Walker A motif in viral genomic DNA cleavage in herpesvirus had been suggested by Przech et al., They found that HSV-1 point-mutated in the Walker A motif within the UL15 exon I failed to cleave viral DNA concatemers and the HSV-1 mutant exhibited growth defects [35].

To date, the taxonomic status of DEV is not clearly defined within the Herpesviridae in ICTVdb [3], although considerable evidence suggests it is a novel member or a member of the Mardivirus genus within the Alphaherpesvirinae $[4,7,8]$. As a genome-wide function-conserved protein among viruses within the Herpesviridae, the DNA packaging-related UL15 is believed to be inherited from a common ancestor by the Alpha-, Beta- and Gamma-herpesviruses [33,36]. This feature makes UL15 an ideal molecular genetic marker for phylogenetic construction and taxonomy within the family. For this reason, the UL15 protein has been widely chosen as one of the markers to characterize the evolutionary relationship of a certain virus within the family Herpesviridae [37-39]. As indicated from the tree based on deduced UL15 amino acid sequence, it is preferable to group the DEV as a member of Mardivirus genus, which is in accordance with the majority of the earlier findings $[4,6,7]$. 


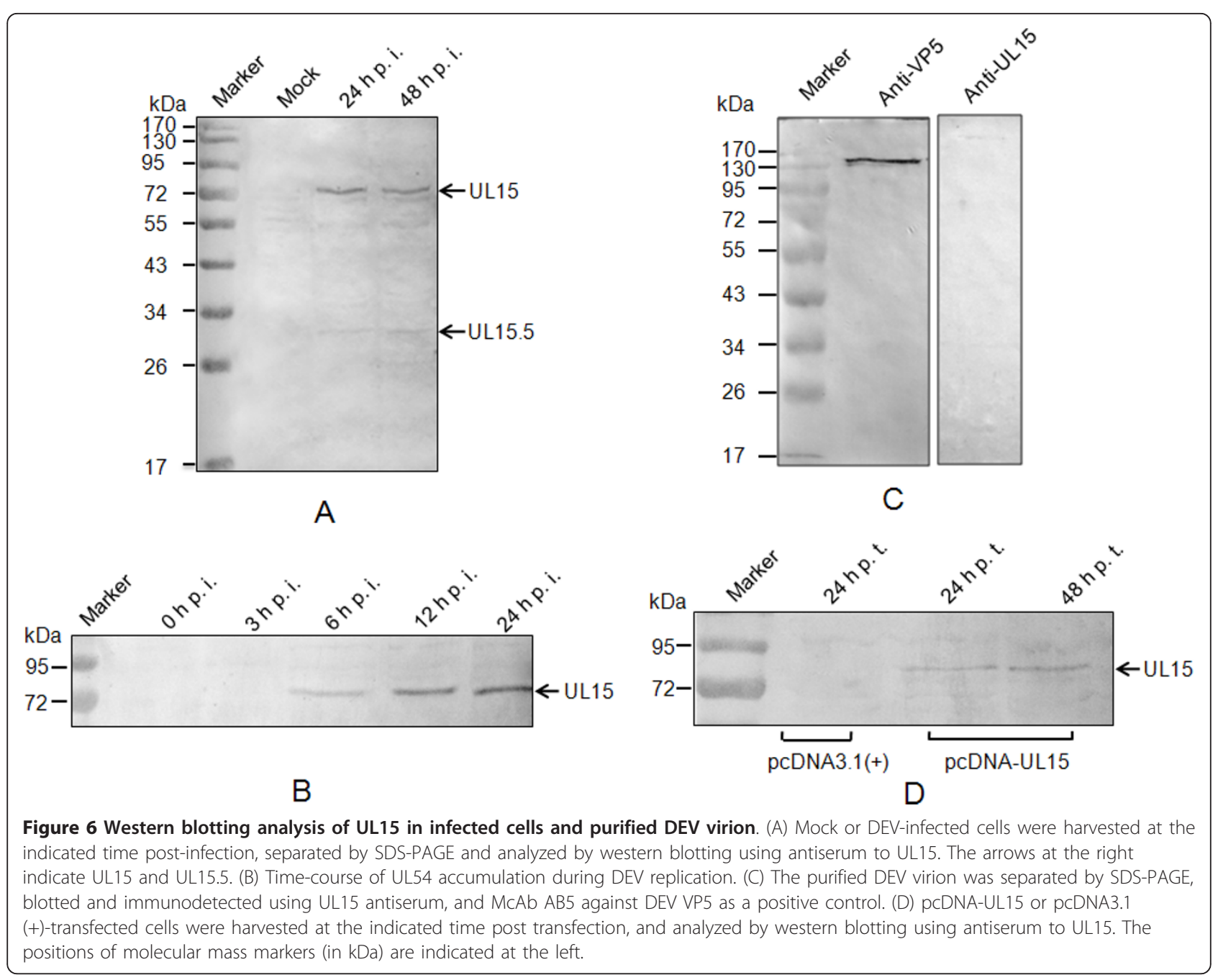

As a component of terminase, UL15 is presumed to interact with replicating DNA and preassembled capsids to cleave and encapsidate the viral DNA. Thus, there exists at least a transient association of DEV UL15 with the capsids. However, UL15 was not detected in the purified DEV virion by western blot (Figure 6C). Two possibilities might account for the failure of UL15 detection. One is that UL15 is not a component of the DEV virion. The other is that it represents a virion component in a so low abundance that it is undetectable by the method used in this study. We would like to infer that the protein is present in the intranuclear capsid precursor however diminished in the mature virion. Theoretically, a mixture of procapsids and A-, B- and $\mathrm{C}$-capsids are present in the DEV virion we have prepared, among which the $\mathrm{C}$-capsid is the predominant type. Furthermore, only a trace amount of UL15 is present in procapsids, A- and B-capsids, whereas the protein might not be present in the more mature DNAcontaining $\mathrm{C}$-capsids, as demonstrated in its counterpart
HSV-1 [40,41]. Therefore, it is possible that UL15 exists in the sucrose density gradient-purified virion, but at such a low abundance that it is not detectable by western blot. Analysis of the virion by more sophisticated techniques, such as immunoelectron microscopy, is needed to confirm this assumption.

Cytoplasmic nuclear transport of UL15 and/or UL15.5 was observed within the DEV-infected cells, which is consistent with the nuclear localization of the protein homologues observed in HSV-1 and VZV-infected cells $[14,21]$. These findings are in line with the fact that the UL15 homologue is a potential terminase subunit since viral DNA cleavage and encapsidation also take place within the nucleus. Interestingly, in HSV-1, UL15 expressed alone displayed efficient nuclear localization [26]; however, findings from VZV ORF45/42 transiently transfected cells as well as those from DEV UL15 in this study suggest that the protein is unable to localize to the nucleus in the absence of any other viral protein. This is not surprising as the UL15 ORF of HSV-1 


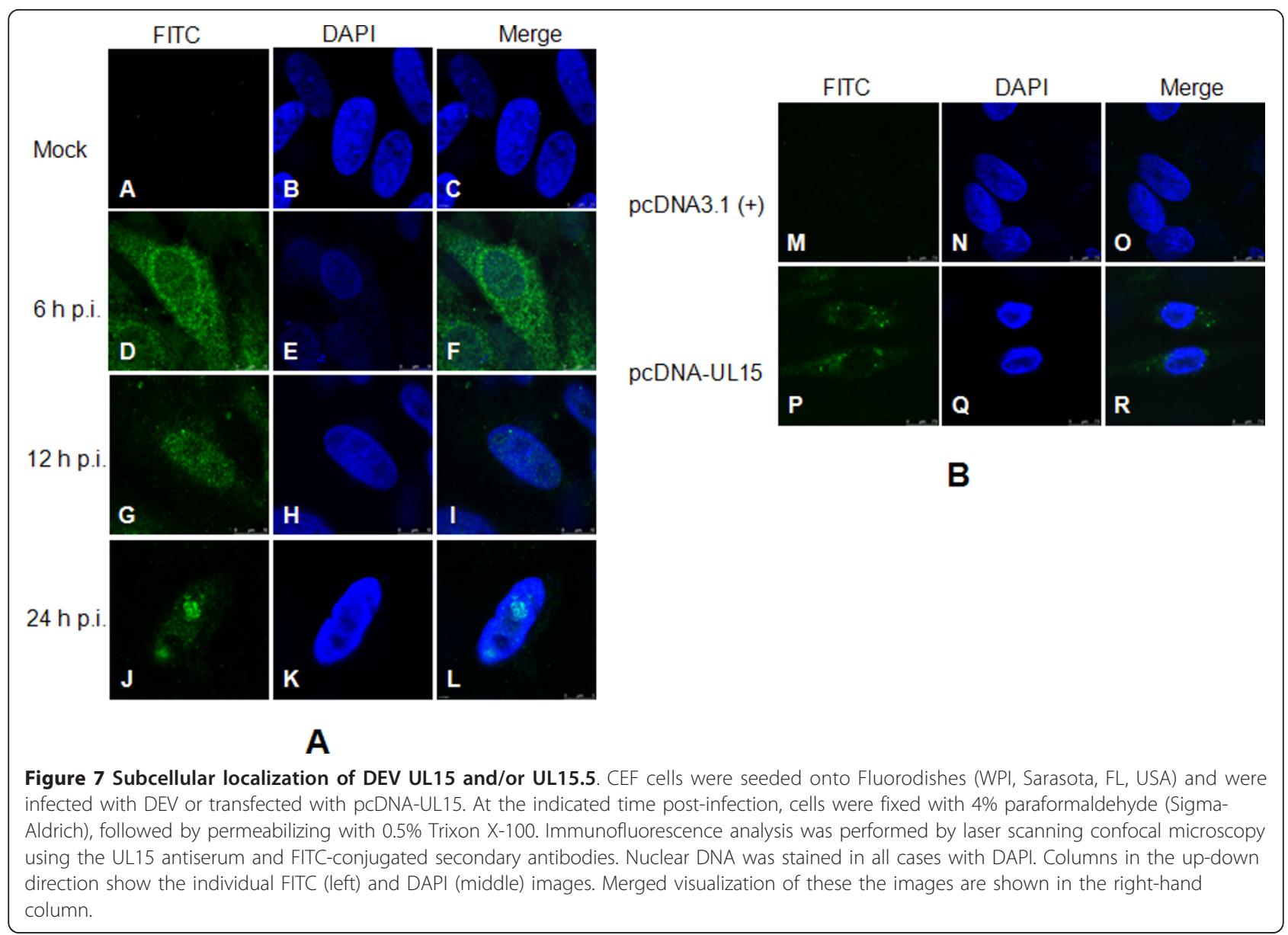

contains a predicted short peptide ( ${ }_{183}$ PPKKRAKV $\left._{190}\right)$ resembling the reported nuclear localization signal (NLS) [21], whereas no similar NLS is predicted in either DEV UL15 or VZV ORF45/42 protein. Besides, ORF 29a/29b, another UL15 homologue from BoHV-4 does not contain a similar NLS sequence either. Hence, we tend to assume that the newly synthesized UL15 is localized in the cytoplasm due to the lack of NLS in DEV-infected cells, whereas transport into the nucleus when coupled with other viral and/or cellular protein(s) that contain NLS to form a protein complex, allowing the nucleus targeting of the protein. Further studies are needed to determine the protein(s) required for the cytoplasmic-nuclear trafficking of UL15 within DEV infected cells.

\section{Conclusions}

DEV UL15 is a spliced gene that encodes two products encoded by 2.9 and $1.3 \mathrm{~kb}$ transcripts respectively. The UL15 is expressed late during infection. The DEV UL15 coding sequences are very similar to those of alphaherpesviruses and most similar to the genus Mardivirus. The UL15 and or UL15.5 accumulate(s) in the cytoplasm during early times post-infection and then are translocated to the nucleus at late times.

\section{Methods}

\section{Cell culture, virus propagation and purification}

Chicken embryo fibroblast (CEF) cells were prepared and maintained in Dulbecco's minimum essential medium (DMEM; Sigma-Aldrich, MA, USA) supplemented with $8 \%$ fetal bovine serum (FBS; JRH Biosciences, KS, USA), $2 \mathrm{mM}$ l-glutamine, 100 units $/ \mathrm{ml}$ penicillin and $100 \mu \mathrm{g} / \mathrm{ml}$ streptomycin. Primary or secondary cells were used to propagate DEV Clone-03, a CEF-adapted vaccine strain [6]. Cells infected with DEV were maintained in DMEM containing 2\% FBS. To prepare the DEV virion, CEF monolayer was infected with DEV Clone-03 at a multiplicity of infection (m. o. i.) of 10 plaque-forming units (p. f. u.)/cell. Cells and the DEVcontaining medium were harvested when more than 80\% CPE developed, followed by 3 cycles of rapid freezing and thawing. The suspension was centrifuged at $4^{\circ} \mathrm{C}$ for $30 \mathrm{~min}$ at $3,000 \times g, 30 \mathrm{~min}$ at $5,000 \times g$ and $30 \mathrm{~min}$ at $8,000 \times g$ to remove cell debris. The supernatant was recovered and centrifuged at $4^{\circ} \mathrm{C}$ for $2 \mathrm{~h}$ at $140,000 \times g$. 
The pellet was suspended in PBS and overlaid onto a discontinuous sucrose density gradient $(20 \%$ and $60 \%$ sucrose in PBS) and centrifuged at $4{ }^{\circ} \mathrm{C}$ for $2.5 \mathrm{~h}$ at $140,000 \times g$ in a Beckman Coulter Optima ${ }^{\mathrm{TM}} \mathrm{L}-100 \mathrm{XP}$ ultracentrifuge equipped with a SW41Ti swingingbucket rotor (Beckman-Coulter, CA, USA). The virus band was collected and diluted with PBS. The virion pellets were finally collected after centrifugation at $4^{\circ} \mathrm{C}$ for $2 \mathrm{~h}$ at 140,000 $\times g$ and suspended in PBS.

\section{Reverse transcription polymerase chain reaction (RT-PCR)} CEF cells were infected with DEV Clone-03 at an $\mathrm{m}$. o. i. of 10. Total RNA was extracted from the infected cells at $48 \mathrm{~h} \mathrm{p}$. i. with TRIzol ${ }^{\circledR}$ reagent (Invitrogen, CA, USA) according to the manufacturer's instruction, followed by reverse transcription with Moloney murine leukemia virus (M-MLV) reverse transcriptase (Invitrogen, CA, USA) and oligo(dT). The UL15 coding sequence was amplified by PCR using the resultant cDNA and the synthetic oligonucleotide UL15f as the forward primer and UL15r as the reserve primer (Table 2). BamHI and HindIII enzyme sites were incorporated into the forward and reverse primer, respectively. In order to verify the splice junction of the UL15 transcript, primers Psjf and Psjr (Table 2) were used to amplify the splice junction from the cDNA. Psjf is homologous to a sequence from exon I, 428 bp upstream from the predicted splice junction and Psjr is antisense to a sequence from exon II, located at a distance of $358 \mathrm{bp}$ from the predicted splice junction. The resultant RT-PCR product was then

Table 2 Primers used in the this study

\begin{tabular}{|c|c|c|}
\hline $\begin{array}{l}\text { Primer } \\
\text { name }\end{array}$ & Primer sequences $\left(5^{\prime}\right.$ to $\left.3^{\prime}\right)$ & Note \\
\hline P15f & ATAGGATCCATGTTCGGGGCAACTITCG & $\begin{array}{l}\text { UL15 forward/ } \\
\text { BamHI }\end{array}$ \\
\hline P15r & GGCAAGCTTTGGTACATATCCTACGTGCGC & $\begin{array}{l}\text { UL15 reverse/ } \\
\text { Hind III }{ }^{\mathrm{a}}\end{array}$ \\
\hline Psjf & TTGAATTATTCCAGAAGATGA & $\begin{array}{l}\text { Splice junction } \\
\text { forward }\end{array}$ \\
\hline Psjr & TTTCTTGCATAAATGAATCG & $\begin{array}{l}\text { Splice junction } \\
\text { reverse }\end{array}$ \\
\hline P898f & AATTTGGGCAACTCAATGGTT & $\begin{array}{l}\text { Northern probe } \\
\text { forward }\end{array}$ \\
\hline P898r & TCTGCCGTACGTCTCATAGC & $\begin{array}{l}\text { Northern probe } \\
\text { reverse }\end{array}$ \\
\hline P15-5 & TGGTGCATGCTCGCAACAGT & $\begin{array}{l}\text { UL15 5'-RACE } \\
\text { primer }\end{array}$ \\
\hline P15.5-5 & TGTTCCAACCCGTATATTAC & $\begin{array}{l}\text { UL15.5'-RACE } \\
\text { primer }\end{array}$ \\
\hline P15-3 & TTACCACTGCGTGCCTCCCA & $\begin{array}{l}\text { UL15 3'-RACE } \\
\text { primer }\end{array}$ \\
\hline Paf & GCGCTCGTTGTTGACA & $\beta$-actin forward \\
\hline Par & TCATCCCAGTTGGTGACA & $\beta$-actin reverse \\
\hline
\end{tabular}

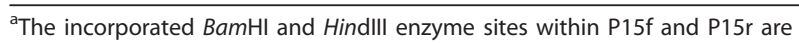
underlined within primer sequences respectively. cloned into the pMD18-T cloning vector (TaKaRa, Dalian, China) and confirmed by sequencing. For kinetic class analysis of UL15 gene, $100 \mu \mathrm{g} / \mathrm{ml}$ cycloheximide (CHX; Sigma-Aldrich, MA, USA) or $300 \mu \mathrm{g} / \mathrm{ml}$ phosphonoacetic acid (PAA; Sigma-Aldrich, MA, USA) was added to the medium $1 \mathrm{~h}$ before infection and maintained at this level for $6 \mathrm{~h}$ and $12 \mathrm{~h}$, respectively. Samples with no metabolic inhibitor served as the control. RT-PCR was then carried out with the same primers as those used for the splice junction analysis with chicken $\beta$-actin mRNA as the internal control.

\section{Amino acid sequence alignment and phylogeny}

Amino acid sequences of terminase orthologues from herpesviruses and bacteriophages were retrieved from the UniProt Knowledgebase (UniProtKB) within the ExPASy proteomics server (http://www.expasy.ch/). Sequences were aligned using the ClastalW2 multiple sequence alignment program with the GONNET 250 scoring matrix [42]. The sequences are as follows: DEV (UniProtKB accession code C6ZD26), HSV-1(P04295), HCMV (P16732), Epstein-Barr virus (EBV, P03219), bacteriophage T4 (P17312), bacteriophage P7 (Q5XLR0) and bacteriophage HK97 (Q9MCT1).

For phylogenetic characterization of DEV within Herpesviridae with respect to the UL15 protein, a maximum likelihood (ML) phylogenetic tree based on the amino acid sequences of 23 deduced UL15 orthologues (Table 3) was constructed. Briefly, A PHYLIP format-output alignment was generated with the ClustalW2 program, with which a phylogram was computed and constructed using PhyML (version 3.0) software with the LG amino acid substitution model. An approximate likelihood ratios test (aLRT) as well as a non-parametric bootstrap support test (100 replicates) was used for phylogenetic tree evaluation. SeaView 4 was used for displaying and editing phylogenetic trees [43].

\section{Northen blot}

Approximately $20 \mu \mathrm{g}$ of total RNA extracted from DEVinfected CEF cells was fractionated by electrophoresis in a $1.2 \%$ agarose gel and transferred onto a positively charged nylon membrane (Immobilon ${ }^{\mathrm{TM}_{-}} \mathrm{Ny}+$, Millipore, MA, USA) by capillary blotting. A DIG High Prime DNA Labeling and Detection Starter Kit I (Roche Applied Science, Mannheim, Germany) was used for probe labeling and northern blot hybridization according to the manufacturer's instructions. Briefly, an 898 bp DNA fragment covering the UL15 splice junction site was amplified by RT-PCR using primers P898f and P898r (Table 2). In addition, the UL15 RT-PCR product was digested $B g l$ II, generating a C-terminus of $696 \mathrm{bp}$. These DNA fragments were purified, labeled with digoxigenin (DIG)-11-dUTP and designated $\mathrm{P}^{898}$, and $\mathrm{PC}^{696}$, 
Table 3 Sequences used for phylogenetic analyses of large terminase orthologs from 23 herpesviruses

\begin{tabular}{|c|c|c|c|c|c|c|}
\hline \multirow[t]{2}{*}{ Subfamily } & \multirow[t]{2}{*}{ Virus species } & \multirow[t]{2}{*}{ Natural host } & \multirow[t]{2}{*}{ Abbreviation } & \multicolumn{2}{|c|}{ Length } & \multirow[t]{2}{*}{ GenBank Accession } \\
\hline & & & & $\mathrm{nt}^{\mathrm{a}}$ & a.a. ${ }^{b}$ & \\
\hline unassigned & Duck enteritis virus & waterfowl & DEV & 2220 & 739 & EF524094/EF203707 \\
\hline \multirow[t]{14}{*}{ Alphaherpesvirinae } & Herpes simplex virus 1 & Human & HSV-1 & 2208 & 735 & FJ593289 \\
\hline & Herpes simplex virus 2 & Human & HSV-2 & 2205 & 734 & Z86099 \\
\hline & Cercopithecine herpesvirus 16 & Monkey and human & CeHV-16 & 2208 & 735 & DQ149153 \\
\hline & Marek's disease virus 1 & Chicken & MDV-1 & 2214 & 737 & AF147806 \\
\hline & Marek's disease virus 2 & Chicken & MDV-2 & 2247 & 748 & AB049735 \\
\hline & Herpesvirus of turkey & Turkey & $\mathrm{HVT}$ & 2217 & 738 & AF291866 \\
\hline & Varicella-zoster virus & Human & VZV & 2232 & 743 & DQ674250 \\
\hline & Bovine herpesvirus 1 & Cattle & $\mathrm{BHV}-1$ & 2208 & 735 & AJ004801 \\
\hline & Bovine herpesvirus 5 & Cattle & BHV-5 & 2214 & 737 & AY261359 \\
\hline & Pseudorabies virus & Swine & PRV & 2208 & 735 & AY189899 \\
\hline & Equine herpesvirus 1 & Horse & $\mathrm{EHV}-1$ & 2205 & 734 & AY665713 \\
\hline & Equine herpesvirus 4 & Horse & $\mathrm{EHV}-4$ & 2205 & 734 & AF030027 \\
\hline & Infectious laryngotracheitis virus & Chicken & ILTV & 2295 & 764 & NC_006623 \\
\hline & Psittacid herpesvirus 1 & Parrots & PsHV & 2388 & 795 & NC_005264 \\
\hline \multirow[t]{3}{*}{ Betaherpesvirinae } & Murine cytomegalovirus & Mouse & MCMV & 2013 & 670 & U68299 \\
\hline & Rat cytomegalovirus & Rat & RCMV & 2013 & 670 & AF232689 \\
\hline & Human herpesvirus 6 & Human & HHV-6 & 2001 & 666 & AF157706 \\
\hline \multirow[t]{5}{*}{ Gammaherpesvirinae } & Epstein-Barr virus & Human & EBV & 2073 & 690 & NC_007605 \\
\hline & Rhesus lymphocryptovirus & Monkey & RhLCV & 2073 & 690 & AY037858 \\
\hline & Human herpesvirus 8 & Huamn & $\mathrm{HHV}-4$ & 2073 & 690 & NC_007605 \\
\hline & Murid herpesvirus 4 & Mouse & MuHV-4 & 2040 & 679 & AF105037 \\
\hline & Bovine herpesvirus 4 & Cattle & BoHV-4 & 2049 & 682 & NC_002665 \\
\hline
\end{tabular}

${ }^{\text {a Nucleotides. }}$

${ }^{\mathrm{b}}$ Amino acids.

CFragments containing exon I and exon II were deposited separately with Accession No. of EF524094 and EF203707 respectively.

respectively. The blots were hybridized at $42^{\circ} \mathrm{C}$ for $4 \mathrm{~h}$ in DIG Easy Hyb buffer followed by hybridization overnight with about $100 \mathrm{ng} / \mathrm{ml}$ labeled probes. Two $5 \mathrm{~min}$ stringency washes with $2 \times$ SSC, $0.1 \%$ SDS were performed at room temperature, followed by two $15 \mathrm{~min}$ washes in $0.5 \times \mathrm{SSC}, 0.1 \% \mathrm{SDS}$ at $68^{\circ} \mathrm{C}$. The hybridized probes were immunodetected with anti-digoxigeninalkaline phosphatase (AP) conjugate and were then visualized with nitroblue tetrazolium/5-bromo-4-chloro3-indolyl phosphate (NBT/BCIP). The size of the mRNA was calculated via the RNA size standard.

\section{Rapid amplification of CDNA ends (RACE)}

The 5'-end sequences of UL15 and UL15.5 transcripts were mapped from the purified mRNA with a 5'-Full RACE Kit (TaKaRa, Dalian, China). Briefly, total RNA was isolated from DEV-infected CEF cells with an E.Z. N.A TM Mag-Bind mRNA Kit (Omega Bio-tek, GA, USA), followed by mRNA purification using the MagBind oligo(dT) magnetic beads supplied with the kit. About $250 \mathrm{ng}$ of the purified mRNA was treated with calf intestinal alkaline phosphatase (CIAP) and tobacco acid pyrophosphatase (TAP) followed by ligation with the 5' RACE adaptor. RT-PCR was performed with the treated RNA using the 5' RACE primer and gene-specific primers P15-5 for UL15 and P15.5-5 for UL15.5 (Table 2). The polyadenylation cleavage site of the transcripts was determined with a 3'-Full RACE Kit (TaKaRa, Dalian, China). RT was done on the total RNA with the 3' RACE adaptor prior to the PCR reaction with the 3' RACE Outer Primer and gene-specific primer P15-3 (Table 2). Occasionally, nested PCR was used for poorly amplified products following the manufacturer's recommendation. The RACE PCR products were cloned into the pMD18-T vector (TaKaRa, Dalian, China), and the inserts were analyzed by sequencing.

\section{Antibodies}

To produce UL15-specific antiserum, a Bgl II and Hind III digested encoding the $\mathrm{C}$-terminal 232 amino acids of UL15 exon II was inserted into the corresponding sites downstream from the T7 promotor of the pET-30a vector (Merck KGaA, Darmstadt, Germany). The recombinant plasmid, designated pET-UL15C ${ }^{232}$, was transformed into Escherichia coli competent cells BL21 (DE3). His 6 -tagged protein was expressed induced with $0.6 \mathrm{mM}$ isopropyl- $\beta$ d-thiogalactopyranoside (IPTG). The cells were then harvested by centrifugation for $15 \mathrm{~min}$ at 3,000 $\times g$. The pellet 
was solubilized, followed by binding to Ni-nitrilotriacetic acid agarose beads (Invitrogen, CA, USA), extensive washing and elution, and the eluted protein was renatured by dialysis. Finally, two male New Zealand white rabbits (Laboratory Animals Center, Harbin Veterinary Research Institute, Harbin, China) were immunized intramuscularly with the purified protein. Serum samples were collected when the ELISA titer reached $1: 10^{4}$. Mouse monoclonal antibody (McAb) 1B5, raised against DEV UL19 (VP5), was prepared in our laboratory previously. Mouse anti- $\beta$ actin antibody was purchased from Sigma-Aldrich Co. (St. Louis, MO, USA).

\section{Plasmid construction and transfection}

The intronless UL15 RT-PCR fragment carrying BamH I and Hind III sites was cloned into the pET-30a vector (Merck KGaA, Germany), giving plasmid pET-UL15. BamH I/Not I double digestion of pET-UL15 released the full-length UL15 ORF, which was cloned directionally into plasmid pcDNA3.1 (+) (Invitrogen, CA, USA) under the control of the human cytomegalovirus (CMV) promoter, generating plasmid pcDNA-UL15. Transient expression of the UL15 gene product was achieved in CEF cells transfected with pcDNA-UL15. Briefly, cells that grew on a coverslip placed into a 6 -well culture plate (Corning, NY, USA) were transfected with $0.5 \mu \mathrm{g}$ of plasmid using the Effectene Transfection Reagent (Qiagen, Hilden, Germany). UL15 expression was analyzed 24-48 h post transfection (h p. t.) with western blot and indirect immunofluorescence assay.

\section{Western blot}

CEF cells were infected with DEV clone-03 in the presence or in the absence of CHX or PAA. Otherwise, CEF cells were transfected with $0.5 \mu \mathrm{g}$ of pcDNA-UL15 or pcDNA3.1 $(+)$ plasmid in 6-well cell culture plates. At different time points, cells were washed twice with PBS then treated with cell lysis buffer $(50 \mathrm{mM}$ Tris- $\mathrm{HCl} \mathrm{pH}$ 8.0, $150 \mathrm{mM} \mathrm{NaCl}, 1 \%$ Triton X-100, $100 \mu \mathrm{g} / \mathrm{ml}$ phenylmethanesulfonyl fluoride) for $20 \mathrm{~min}$. After centrifugation at $4^{\circ} \mathrm{C}$, cell lysates were mixed with $5 \times$ SDS sample buffer $(250 \mathrm{mM}$ Tris- $\mathrm{HCl} \mathrm{pH} 6.8,10 \%$ SDS, $5 \% \beta$-mercaptoethanol, $50 \%$ glycerol, $0.05 \%$ bromophenol blue), boiled for $5 \mathrm{~min}$ and then analyzed by SDS-polyacrylamide gel electrophoresis (PAGE). Fractionated proteins were electrotransferred onto a nitrocellulose membrane (Millipore, MA, USA), after which the membrane was incubated in blocking solution $(0.1 \%$ Tween- 20 and $5 \%$ nonfat dry milk in PBS) at $4^{\circ} \mathrm{C}$ overnight, followed by reaction for $1 \mathrm{~h}$ at room temperature with the antibodies in appropriate dilution (1:200 for anti-UL15, 1:5,000 for anti- $\beta$ actin), washed extensively in PBST (0.1\% Tween-20 in PBS) followed by reaction for $2 \mathrm{~h}$ with 1:5000 diluted horseradish peroxidase-conjugated immunoglobulin
(Sigma-Aldrich, MA, USA). After several washes in PBST, the bands were visualized by incubating the membrane in freshly prepared DAB solution (2.5 $\mathrm{mg}$ of 3,3-diaminobenzidine tetrahydrochloride in $10 \mathrm{ml}$ of Tris- $\mathrm{HCl}$ buffer, $\mathrm{pH}$ 7.5) containing $0.03 \% \mathrm{H}_{2} \mathrm{O}_{2}$.

\section{Immunofluorescence}

Secondary CEF cells were grown on Fluorodishes (WPI, FL, USA.) and were either infected with DEV Clone-03 or transfected with $0.5 \mu \mathrm{g}$ of pcDNA-UL15. At different time point post-infection, cells were fixed with $4 \%$ paraformaldehyde (Sigma-Aldrich, MA, USA) for $20 \mathrm{~min}$ at room temperature, followed by permeabilizing with $0.5 \%$ Trixon X-100 for $10 \mathrm{~min}$. For cells transfected with plasmids, this procedure was done at $24 \mathrm{~h}$ or $48 \mathrm{~h}$ posttransfection. After brief washing, cells were blocked in $10 \%$ horse serum to avoid high background levels, and then incubated in 1:400 diluted UL15-specific antiserum overnight at $4{ }^{\circ} \mathrm{C}$. The cells were rinsed extensively, and then reacted with fluorescein isothiocyanate (FITC)-conjugated goat anti-rabbit immunoglobulin (Sigma-Aldrich, MA, USA) diluted 1:80. Nuclei were counter-stained with 4'-6-diamidino-2-phenylindole (DAPI; Sigma-Aldrich, MA, USA) as recommended by the manufacturer. Laser scanning confocal microscopy was performed with a Leica TCS SP5 microsystem (Leica, Mannheim, Germany).

Authors' contributions

$\mathrm{HZ}$ and $\mathrm{XK}$ designed the research; $\mathrm{HZ}, \mathrm{HL}, \mathrm{ZH}, \mathrm{YS}$ and $\mathrm{YW}$ performed research; $\mathrm{HZ}, \mathrm{HL}$ and $\mathrm{YW}$ analyzed data; $\mathrm{HZ}$ and $\mathrm{XK}$ contributed to drafting the manuscript. All authors read and approved the final manuscript.

\section{Competing interests}

The authors declare that they have no competing interests.

Received: 13 December 2010 Accepted: 6 April 2011

Published: 6 April 2011

\section{References}

1. Davison S, Converse KA, Hamir AN, Eckorage RJ: Duck viral enteritis in domestic Muscovy ducks in Pennsylvania. Avian Dis 1993, 37:1142-1146.

2. Keymer IF, Gough RE: Duck virus enteritis (anatid herpesvirus infection) in mute swans (Cygnus Olor). Avian Pathol 1986, 15:161-170.

3. Fauquet CM, Mayo MA: The Double stranded DNA viruses. In Virus Taxonomy: Eighth Report of the International Committee on Taxonomy of Viruses. Edited by: Fauquet CM, Mayo MA, Maniloff J, Desselberger U, Ball LA. California: Elsevier Academic Press; 2005:208, Chapter 6.

4. Liu S, Chen S, Li H, Kong X: Molecular characterization of the herpes simplex virus 1 (HSV-1) homologues, UL25 to UL30, in duck enteritis virus (DEV). Gene 2007, 401:88-96.

5. Liu X, Liu S, Li H, Han Z, Shao Y, Kong X: Unique sequence characteristics of genes in the leftmost in the leftmost region of unique long region in duck enteritis virus. Intervirology 2009, 52:291-300.

6. Li H, LiU S, Kong X: Characterization of the genes encoding UL24, TK and $\mathrm{gH}$ proteins from duck enteritis virus (DEV): a proof for the classification of DEV. Virus Genes 2006, 33:221-227.

7. Li H, LiU S, Han Z, Shao Y, Chen S, Kong X: Comparative analysis of the genes UL1 through UL7 of the duck enteritis virus and other herpesviruses of the subfamily Alphaherpesvirinae. Genet Mol Biol 2009, 32:121-128. 
8. Li Y, Huang B, Ma X, Wu J, Li F, Ai W, Song M, Yang H: Molecular characterization of the genome of duck enteritis virus. Virology 2009, 391:151-161.

9. Costa RH, Draper KG, Kelly TJ, Wagner EK: An unusual spliced herpes simplex virus type 1 transcript with sequence homology to Epstein-Barr virus DNA. J Virol 1985, 54:317-328.

10. Broll H, Finsterbusch T, Buhk HJ, Goltz M: Genetic analysis of the bovine herpesvirus type 4 gene locus for the putative terminase. Virus Genes 1999, 19:243-250.

11. Gruijthuijsen YK, Beuken E, Bruggeman CA, Vink C: Rat cytomegalovirus R89 is a highly conserved gene which expresses a spliced transcript. Virus Res 2000, 69:119-130.

12. Bahr B, Tobiasch E, Darai G: Structural organization and analysis of the viral terminase gene locus of Tupaia herpesvirus. Virus Res 2001, 74:27-38.

13. Kingham BF, Zelník V, Kopácek J, Majercíak V, Ney E, Schmidt CJ: The genome of herpesvirus of turkeys: comparative analysis with Marek's disease viruses. J Gen Virol 2001, 82:1123-1135.

14. Visalli RJ, Nicolosi DM, Irven KL, Goshorn B, Khan T, Visalli MA: The varicellazoster virus DNA encapsidation genes: identification and characterization of the putative terminase subunits. Virus Res 2007, 129:200-211.

15. Fuchs W, Klupp BG, Granzow H, Leege T, Mettenleiter TC: Characterization of pseudorabies virus (PrV) cleavage-encapsidation proteins and functional complementation of PrV pUL32 by the homologous protein of herpes simplex virus type 1. J Virol 2009, 83:3930-3943.

16. Davison AJ: Channel catfishvirus: a new type of herpesvirus. Virology 1992, 186:9-14

17. Mitchell MS, Matsuzaki S, Imai S, Rao VB: Sequence analysis of bacteriophage T4 DNA packaging/terminase genes 16 and 17 reveals a common ATPase center in the large subunit of viral terminases. Nucleic Acids Res 2002, 30:4009-4021.

18. Black L: DNA packaging in dsDNA bacteriophages. Annu Rev Microbiol 1989, 43:267-292.

19. Addison C, Rixon FJ, Preston VG: Herpes simplex virus type 1 UL28 gene product is important for the formation of mature capsids. J Gen Virol 1990, 71:2377-2384.

20. Al-Kobaisia MF, Rixona FJ, McDougalla I, Preston VG: The herpes simplex virus UL33 gene product is required for the assembly of full capsids. Virology 1991, 180:380-388.

21. Baines JD, Poon APW, Rovnak J, Roizman B: The herpes simplex virus 1 UL15 gene encodes two proteins and is required for cleavage of genomic viral DNA. J Virol 1994, 68:8118-8124

22. Lamberti C, Weller SK: The herpes simplex virus type 1 UL6 protein is essential for cleavage and packaging but not for genomic inversion. Virology 1996, 226:403-407.

23. McNab AR, Desai P, Person S, Roof LL, Thomsen DR, Newcomb WW Brown JC, Homa FL: The product of the herpes simplex virus type 1 UL25 gene is required for encapsidation but not for cleavage of replicated viral DNA. J Virol 1998, 72:1060-1070.

24. Salmon B, Cunningham C, Davison AJ, Harris WJ, Baines JD: The herpes simplex virus type 1 UL17 gene encodes virion tegument proteins that are required for cleavage and packaging of viral DNA. J Virol 1998, 72:3779-3788.

25. Schaffer PA, Aron GM, Biswal N, Benyesh-Melnick M: Temperature-sensitive mutants of herpes simplex virus type 1: isolation, complementation and partial characterization. Virology 1973, 52:57-71.

26. Yu D, Weller SK: Genetic analysis of the UL15 gene locus for the putative terminase of herpes simplex virus type 1. Virology 1998, 243:32-44.

27. Abbotts AP, Preston VG, Hughes M, Patel AH, Stow ND: Interaction of the herpes simplex virus type 1 packaging protein UL15 with full-length and deleted forms of the UL28 protein. J Gen Virol 2000, 81:2999-3009.

28. Koslowski K, Shaver PR, Casey JT II, Wilson T, Yamanaka G, Sheaffer AK, Tenny DJ, Pederson N: Physical and functional interactions between the herpes simplex virus UL15 and UL28 DNA cleavage and packaging proteins. J Virol 1999, 73:1704-1707.

29. Wills E, Scholtes L, Baines JD: Herpes simplex virus 1 DNA packaging proteins encoded by UL6, UL15, UL17, UL28, and UL33 are located on the external surface of the viral capsid. J Virol 2006, 80:10894-10899.

30. Scheffczik H, Savva CG, Holzenburg A, Kolesnikova L, Bogner E: The terminase subunits pUL56 and pUL89 of human cytomegalovirus are
DNA-metabolizing proteins with toroidal structure. Nucleic Acids Res 2002, 30:1695-1703.

31. Keller $E B$, Noon WA: Intron splicing: a conserved internal signal in introns of animal pre-mRNAs. Proc Natl Acad Sci USA 1984, 81:7417-7420.

32. Ward PL, Ogle WO, Roizman B: Assemblons: Nuclear structures defined by aggregation of immature capsids and some tegument proteins of herpes simplex virus 1. J Virol 1996, 70:4623-4631.

33. Wang N, Baldi PF, Gaut BS: Phylogenetic analysis, genome evolution and the rate of gene gain in the Herpesviridae. Mol Phylogenet Evol 2007, 43:1066-1075.

34. Liu S, Li H, Li Y, Han Z, Shao Y, An R, Kong K: Phylogeny of Duck Enteritis Virus: Evolutionary Relationship in the Family Herpesviridae. Intervirology 2008, 51:151-165

35. Przech AJ, Yu D, Weller SK: Point mutations in Exon I of the herpes simplex virus putative terminase subunit, UL15, indicate that the most conserved residues are essential for cleavage and packaging. J Virol 2003, 77:9613-9621.

36. Davison AJ: Evolution of the herpesviruses. Vet Microbiol 2002, 86:69-88.

37. McGeoch DJ, Dolan A, Ralph AC: Toward a comprehensive phylogeny of mammalian and avian herpesviruses. J Virol 2000, 74:10401-10406.

38. Albà MM, Das R, Orengo CA, Kellam P: Genomewide function conservation and phylogeny in the Herpesviridae. Genome Res 2001, 11:43-54.

39. McGeoch DJ, Rixon FJ, Davison AJ: Topic in herpesvirus genomics and evolution. Virus Res 2006, 117:90-104.

40. Sheaffer AK, Newcomb WW, Gao M, Yu D, Weller SK, Brown JC, Tenney DJ: Herpes simplex virus DNA cleavage and packaging proteins associate with the procapsid prior to its maturation. J Virol 2001, 75:687-698.

41. Beard PM, Duffy C, Baines JD: Quantification of the DNA cleavage and packaging proteins UL15 and UL28 in A and B Capsids of herpes simplex virus type 1. J Virol 2004, 78:1367-1374

42. Larkin MA, Blackshields G, Brown NP, Chenna R, McGettigan PA, McWilliam H, Valentin F, Wallace IM, Wilm A, Lopez R, et al: ClustalW and ClustalX version 2. Bioinformatics 2007, 23:2947-2948.

43. Gouy M, Guindon S, Gascuel O: SeaView version 4: a multiplatform graphical user interface for sequence alignment and phylogenetic tree building. Mol Biol Evol 2010, 27:221-224.

doi:10.1186/1743-422X-8-156

Cite this article as: Zhu et al:: Identification of a spliced gene from duck enteritis virus encoding a protein homologous to UL15 of herpes simplex virus 1. Virology Journal 2011 8:156.

\section{Submit your next manuscript to BioMed Central and take full advantage of:}

- Convenient online submission

- Thorough peer review

- No space constraints or color figure charges

- Immediate publication on acceptance

- Inclusion in PubMed, CAS, Scopus and Google Scholar

- Research which is freely available for redistribution

Submit your manuscript at www biomedcentral com/submit
C Biomed Central 